\title{
Clinical teachers working in hospitals: a New Zealand perspective
}

\author{
Marcus Henning ${ }^{1}$, Ralph Pinnock ${ }^{2}$, Warwick Bagg ${ }^{3}$, Boaz Shulruf ${ }^{4}$, Susan J Hawken ${ }^{5}$
}

\begin{abstract}
Introduction: The perceptions and actions of clinical teachers working in hospitals influence their teaching, how their students' learn and the clinical learning environment. The research question was, "what are the views of clinical teachers in relation to what needs to be changed in the School of Medicine?"

Materials and methods: A total of 80 hospital clinical teachers involved in teaching general medicine, obstetrics and genecology, paediatrics, psychiatry, and surgery contributed to this study. The teachers were self-selected and expressed their perceptions in response to an open-ended question, 'If you could change three things about medical school - what would they be?' To derive meaning from the open-ended comments the Colaizzi phenomenological method was adapted. Additionally, six items were constructed to allow teachers to rate their level of agreement on key areas of teaching.

Results: The clinical teachers' commentaries indicated that the main themes were in areas of curriculum and selection of students, teaching, service and research commitments, and professional development. The level of agreement data supported the commentaries and showed no differences across the clinical disciplines.Discussion: The findings of this study affirmed the need for further cohesion between the medical programme and the hospitals in terms of directing and integrating the curriculum. It is imperative that non-faculty clinician teachers have allocated time to teach and are rewarded for their work. Teach the teacher initiatives need to be developed to assist clinical teachers in meeting their teaching responsibilities in their hospital settings.
\end{abstract}

Key words: clinical environment, medical curriculum

\footnotetext{
${ }^{1}$ Senior Lecturer, Centre for Medical and Health Sciences Education, Private Bag 92019, University of Auckland, New Zealand.

${ }^{2}$ Head of Discipline, Child and Adolescent Health. Senior Staff Specialist in Paediatrics, The Townsville Hospital, Australia. Honorary Consultant Paediatrician, Starship Children's Hospital, Auckland, New Zealand.

${ }^{3}$ Associate Professor, Department of Medicine, University of Auckland, Private Bag 92019, University of Auckland, New Zealand

${ }^{4}$ Associate Professor, Medical Education, Faculty of Medicine, University of New South Wales, Sydney, NSW, Australia.

${ }^{5}$ Senior Lecturer, Department of Psychological Medicine, Faculty of Medical and Health Sciences, Private Bag 92019, University of Auckland, New Zealand.

Corresponding author:

Marcus A. Henning, Senior Lecturer, Centre for Medical and Health Sciences Education, Private Bag 92019, University of Auckland, New Zealand.
}

\section{Introduction}

The critical nature of clinical teaching in hospitals has been well researched. Teaching at the bedside allows for opportunities to engage students in terms of medical ethics, people skills involved with patient care, and role-modelling of professional behaviour. This study adds to the descriptive tapestry related to the challenges that clinical teachers face and the consequent opportunities that arise when working in a vibrant and dynamic learning environment (Dolmans et al. 2008; McCann, Naden \& Child 2009; Reed et al. 2007). This study is an extension of previous work in this area as it asks clinical teachers working in hospitals about their relationships with the university and, more specifically, the areas that they would like modified.

Other studies in this research area have focused on describing the views of teachers. 
For example, Alexander and Haldane (1981) investigated differences between pre-clinical and clinical teachers in terms of their views about medical education. These researchers found that clinical teachers were different to pre-clinical teachers in several areas. Clinical teachers experienced more challenges related to: (1) acquiring teaching competence given that they were primarily employed for clinical capability; (2) acquiring and responding to formative feedback from students and accessing educational technologies; and (3) acquiring information on the academic progress of students. Several issues have been more recently raised in the literature that include: the provision of teaching for clinical teachers, resourcing teaching, and recruitment (Dogra et al. 2008). Other issues hindering clinical teacher effectiveness include time-related concerns (Reed et al. 2007; Zibrowski, Weston \& Goldszmidt 2008; McCann, Naden \& Child 2009), motivational factors (Wright \& Beasley 2004; McCann, Naden \& Child 2009), and prioritization of tasks (Zibrowski, Weston \& Goldszmidt 2008). These are real issues facing teachers in clinical education. The source of the issue may be organisational (hospital or university or both), personal, or professional.

Masunaga and Hitchcock (2010) found that both residents and faculty in a North American setting were in agreement as to the characteristics of an ideal clinician teacher. Some of the characteristics cited were "stimulating, encouraging, competent, and communicating and are not conventional, cautious, or controlling" (p. 118). These authors also noted that faculty members had more responsibility than residents in terms of teaching and ensuring competency requirements. To ensure clinical teachers acquire these ideal characteristics, there have been several teach the teacher initiatives to address problems related to clinical teacher proficiency (Johansson, Skeff \& Stratos 2009; Schwartz 2010; Molenaar et al. 2009; Masunaga \& Hitchcock 2010). Teach the teacher initiatives (Arena, Arnolda \& Lake 2008; Lake 2004) are crucial to developing strong education and research-based links between the universities and the hospital learning environment and these links can build on administrative networks already in place (Henning, Hazell \& Shulruf 2011, January 29).

The present study used a qualitative approach to investigate the views of clinical teachers working in hospitals with respect to their involvement with students in early clinical training. The overarching research question was, 'What would clinical teachers like to change about medical school?' The term "medical school" was chosen as a commonly used generic term.

\section{Method}

\section{Participants}

A total of 80 hospital clinical teachers contributed to this study. Administrators within departments in the hospital system purposively targeted clinical teachers and the volunteer sample was self-selected from this pool with an estimated response rate of above $60 \%$ (Pinnock et al. 2011). From the total sample, the following proportions for each clinical discipline were computed: medicine $(19 \%)$, obstetrics and genecology $(17.5 \%)$, paediatrics $(21 \%)$, psychiatry $(12.5 \%)$, and surgery $(30 \%)$. These teachers were teaching in hospitals within the greater Auckland region and Hamilton and had teaching responsibilities associated with the Faculty of Medical and Health Sciences (FMHS) at The University of Auckland.

\section{Procedure}

Questionnaires were sent to clinical teachers who teach year 4 and year 5 students in the FMHS medical programme at The University of Auckland. The questionnaires were then anonymously returned to the administrator and distributed to the researchers for analysis. The FMHS medical programme is usually a sixyear programme, which includes year 1 of the Bachelor of Health Sciences or the Bachelor of Science in Biomedical Science. During the first three years students concentrate on learning the sciences that underpin clinical practice followed by a focus on learning in clinical environments. The final year is a trainee intern year where students have limited clinical responsibilities under supervision (The University of Auckland: Faculty of Medical and Health Sciences).

The teachers were asked to bear in mind their recent experiences when teaching medical students within their hospital environs. The questionnaire comprised of an open endedquestion and six quantifiable items. The open ended question posed was: 'If you could change three things about medical school - 
what would they be?' To consider the underlying meanings associated with the openended comments Colaizzi's phenomenological method was incorporated (Sanders 2003). The six-item questionnaire comprised five options (strongly agree, agree, neutral, agree, and strongly agree). The items were worded as: (1) I feel confident to teach students; (2) I have sufficient time to teach students; (3) learning objectives are clear; (4) there are sufficient clinical learning opportunities for students' needs; (5) feedback was given regularly; and (6) students feel part of the team. Given the non-parametric nature of the data, a KruskalWallis test (Field 2005) was used to test for differences across teams (medicine, obstetrics and genecology, paediatrics, psychiatry, and surgery). The study was approved by The University of Auckland Human Participant Ethics Committee.

\section{Results}

The following findings consider both the qualitative and quantitative responses to the questionnaire. First, summaries of clinical teachers' data were derived from the openended item. Several themes were determined to encapsulate the responses obtained from the clinical teachers. The themes were broadly defined in reference to: (1) curriculum and selection of students; (2) teaching, service and research; and (3) professional development. Second, the response data to the six items were considered.

\section{Curriculum and selection of students}

The notion of developing teamwork and exposing students to more clinical work was something that those surveyed felt was needed to be explicitly built into the curriculum. For example, one clinician teacher commented,

"Medical students should be more involved in the team on the rotation and have more exposure to activities such as supervised clerking of patients".

Another area that surfaced was related to the teaching of content,

"More teaching on pharmaceutical and other[content]relevant to treatment decisions".

A further concern was the need for more inter professional learning experiences,

"[Students] should train with nurses and other disciplines".
Lastly, the issue of assessment was raised, "One of my frustrations in teaching medical students [..], was the emphasis on multiple choice examinations (which works against problem solving and articulate discourse) and the pressure students feel regarding these exams, so that every lecture is supposed to be based on 'what's on the exam' or else it disappoints the student audience".

The issue of selection and student attitude to clinical training also emerged. One participant commented,

"[Students] would require some life experience before enrolment".

Some clinical teachers had very specific comments related to linguistic and entry criteria -

"Admit only students who are born in New Zealand and are fluent in English".

"Entrance based on academic performance".

\section{Teaching, service and research}

The second theme was evidenced by comments in relation to balance and juggling service, resources and time. One participant explicitly stated that they needed,

"More time to teach - very difficult with clinical duties/on calls/full clinics etc".

Another participant was aware of the trade-off between teaching, clinical work and patient care,

"Reduce clinical teaching load unless full and proper consultation regarding impact on teacher and clinical services/patient care".

A further participant indicated that they found the student load too much to deal with,

"Fewer [students] at a time in the clinical setting" and "smaller groups for bedside teaching".

Other participants emphasised that it was difficult to meet the demands of the students due to staff shortages and a lack of resources,

"More senior educational project officers to help academic and clinical staff with the myriad tasks in providing quality, integrated, outcomes based education for medical students". 
There was also a clear message in the comments that one clinical teacher felt undervalued,

"Create an environment in which staff feels valued".

Some commented that the value of a teacher was not rewarded in the same light as researchers,

"More time and more reward for good educators - value as research achievements are valued".

And this lack of acceptance may impact on the way students are accepted in the wards, as one participant stated,

"Friendlier, more approachable atmosphere for students".

\section{Professional development}

One participant wanted the medical school to have, "Closer links with hospitals"
In addition, the notion of closer links was likely to enable a more transparent nexus between the theory of education and the actual practice of clinical education. One clinical teacher posed the following idea,

"I would introduce a system of teaching students how to teach from early on. Learning to teach later is often too late. By teaching they will learn more".

\section{Questionnaire responses}

First, the internal consistency of the six questions was confirmed; and the Cronbach's alpha coefficient $(\alpha=.71)$ indicated strong unidimensionality. Content and face validity was established following a robust appraisal from an experienced clinical teacher and research forum.

Second, clinician teacher responses to the items (Table 1) showed that clinician teachers strongly agreed with four items (confidence to teach students, sufficient clinical learning opportunities, provision of regular feedback, and being part of the team). However, there is disparity in the two remaining items (sufficient time to teach and clarity of learning objectives, item 2 and 3 ).

Table 1. Frequency data $(n=80)$ for each of the items in relation to the five options showing the distribution of responses across response options according to each item

\begin{tabular}{|c|c|c|c|c|c|}
\hline Item & $\begin{array}{l}\text { Strongly } \\
\text { disagree }\end{array}$ & Disagree & Neutral & Agree & $\begin{array}{l}\text { Strongly } \\
\text { agree }\end{array}$ \\
\hline I feel confident to teach students & & & $5(6 \%)$ & $37(46 \%)$ & $38(48 \%)$ \\
\hline I have sufficient time to teach student & $6(8 \%)$ & $14(18 \%)$ & $21(26 \%)$ & $33(41 \%)$ & $6(8 \%)$ \\
\hline Learning objectives are clear & $8(10 \%)$ & $15(19 \%)$ & & $39(49 \%)$ & $18(23 \%)$ \\
\hline $\begin{array}{l}\text { There are sufficient clinical learning } \\
\text { opportunities for students' needs }\end{array}$ & $1(1 \%)$ & $5(6 \%)$ & $15(19 \%)$ & $39(49 \%)$ & $20(25 \%)$ \\
\hline Feedback was given regularly & $1(1 \%)$ & $5(6 \%)$ & $15(19 \%)$ & $39(49 \%)$ & $20(25 \%)$ \\
\hline $\begin{array}{l}\text { Students feel part of the team on the } \\
\text { rotation }\end{array}$ & $2(3 \%)$ & $8(10 \%)$ & $21(26 \%)$ & $32(32 \%)$ & $10(13 \%)$ \\
\hline
\end{tabular}

Responses to the brief questionnaire were evaluated using a Kruskal-Wallis test of significance (Table 2). No significant differences were noted for any of the items across the disciplines indicating all disciplines responded to the items equivalently. 
Table 2. Kruskal Wallis test results $(n=80)$ to appraise the distribution of scores for each item across the clinical disciplines (medicine, obstetrics and genecology, paediatrics, psychiatry, and surgery)

\begin{tabular}{llll}
\hline Item & $\chi^{2}$ & df & $p$ \\
\hline I feel confident to teach students & 2.65 & 4 & .62 \\
I have sufficient time to teach student & 1.23 & 4 & .87 \\
Learning objectives are clear & 3.60 & 4 & .46 \\
There are sufficient clinical learning opportunities for & 2.35 & 4 & .67 \\
students' needs & & & \\
Feedback was given regularly & 6.05 & 4 & .20 \\
Students feel part of the team on the rotation & 9.06 & 4 & .06 \\
\hline
\end{tabular}

\section{Discussion}

The purpose of this study was to explore the opinions and thoughts of clinical teachers working in the hospital environment in relation to what they would like changed in the 'medical school'. The FMHS medical programme is currently faced with an increase in the intake of entrants (New Zealand Medical Students' Association 2008), which further motivated the present researchers to consider clinical teachers' needs in working in the hospitals in terms of faculty support.

The participants who responded to this survey have clearly articulated several themes related to: (1) curriculum and selection of students; (2) teaching, service and research; and (3) professional development. The following discussion addresses each of these themes in turn.

\section{Curriculum and selection of students}

Curriculum issues are clearly identified by clinical teachers' in this study and encompass areas related to team involvement and exposure to clinical activities, teaching of content, inter-professional learning and assessment. Moreover, clinical teachers appeared to be divided in terms of developing clear learning objectives. A starting point for addressing these issues is clarification about ownership of curriculum. This question is very pertinent and is related to the notions of leadership, communication and integration. Roberts and colleagues (2003) considered the issue of ownership when developing a networked learning environment in the UK.

The first step is to determine the key stakeholders that likely include teaching staff, the community and the students and an overriding vision statement to drive the process of change or refinement. The system needs to integrate core facets of curricula in terms of content and process with key personnel. The process needs to involve aspects of planning, action, auditing and reflection that is driven by the leadership of a Curriculum Committee (Roberts et al. 2003).

Selection of medical students is also an important area of inquiry and was raised by clinical teachers in this study. Prideaux and colleagues (2011) have reviewed the current state of play in the selection debate.

In this comprehensive review, these authors recommend that selection needs to adhere to the same rigour as assessment in reference to establishing reliability and validity, defining appropriate domains and attributes and ensuring programmatic review. Selection needs to be cognisant of the transitional stages in the development of doctors as they progress through their degree and into professional practice (Prideaux et al. 2011).

Detailed descriptions outline the selection processes implemented for medical programmes in New Zealand (Mckimm et al. 2010; Collins \& White 1993; Shulruf, Hattie \& Tumen 2008). It is important to note that the FMHS medical programme has a system for constantly reviewing medical student selection policies (Poole et al. 2009) and the issue is currently being rigorously debated in light of workforce needs, the changing demographics of the population, the aging population and increasing student numbers. A reinvigorated curriculum is envisaged for 2013. 
Teaching, service, and research

The findings in this study indicate that clinical teachers would like input from the universities in reference to developing a balance between clinical duties, service, and teaching roles. There is also a clear feature in the comments indicating a sense of being undervalued. The problem of balance and value has also been highlighted elsewhere both locally (McCann, Naden \& Child 2009) and globally (Zibrowski, Weston \& Goldszmidt 2008). In their study, McCann and colleagues (2009) noted that balance and promoting a sense of value could be remediated through several avenues that include increasing the resources for teachers and considering remuneration options, developing courses that can enhance teaching competence, certification of teachers, and developing the teaching and learning environment.

The commentaries revealed concerns with respect to accessing available time to teach. A logical starting point for remediating this problem is to create protected non-clinical time, specifically tagged for teaching (Nair, Coughlan \& Hensley 1998). In their paper, Zibrowski and colleagues (2008) acknowledged that the problem of time is, "complex and multifaceted' and access to time for education can often be termed 'opportunistic'. Teaching roles are often 'at odds' with other roles and clinicians interested in teaching often go beyond the 'call of duty'. In addition, teaching requires a series of steps encompassing preparation, implementation, feedback, and reflection (Driessen, Tartwijk \& Dornan 2008; Steinert 2008). The use of time in a teaching session has also been considered, and it is essential to ensure a learning-centred approach to guarantee learner commitment and a professional attitude to the teaching session (Steinert 2008; Neher et al. 1992). These issues are often related to professional development and learning new skills such as 'how to teach on the run' (Lake 2004).

\section{Professional development}

The clinical teachers in this study further emphasised a need for greater professional development initiatives from the FMHS medical programme. Teach the teacher series incorporated to address the needs of clinical educators have been formally implemented overseas (Arena, Arnolda \& Lake 2008; Lake 2004) and have become an informal activity within the upper north island of New Zealand (Henning, Hazell \& Shulruf 2011, January 29). Some of the areas being addressed include how to teach when busy, using appropriate pitch, developing assessment tools, and harnessing effective feedback systems (Henning, Hazell \& Shulruf 2011, January 29). Therefore, a comprehensive and formalised 'teach the teacher' series developed by the universities in conjunction with teaching units in hospitals would likely have several outcomes that include developing a closer nexus, reciprocity and a more coordinated lobby platform. This education lobby platform could approach the government for more resources and pecuniary contributions.

\section{Overall conclusion}

The aim of the present study was to collect and collate the views of clinical teachers working with students from the FMHS medical programme. The probe question aimed to elicit useful comments from clinical teachers that could inform further development and enhancement of the medical programme. The commentaries affirmed the need for further cohesion between the medical programme and the hospitals in terms of directing and integrating the curriculum. It is crucial that nonfaculty clinicians have representation and a voice on curriculum committees that consider issues of content, selection and assessment. It is also important to make certain that nonfaculty clinician teachers have allocated time to teach and are rewarded for their work. Teach the teacher initiatives could be further developed and formalised as this would assist clinical teachers in meeting their teaching responsibilities in their hospital settings.

It is further important to acknowledge that this study was region specific and thus may not readily be generalisable to other regions in New Zealand or overseas. It is also acknowledged that the probe question and brief questionnaire used to extract information in this study are intermediary points and further research using other methodological techniques such as more expansive survey methods, interviews and focus groups may expand and elucidate some of the ideas presented in this paper.

\section{References}

Alexander, D. \& Haldane, J. (1981) Medical education: the observations of pre clinical and clinical teachers, Medical Education, 15, 1, pp. 4-10.

Arena, G., Arnolda, L. \& Lake, F. (2008) Addressing the needs of clinical teachers: action research, The Clinical Teacher, 5, 3, pp. 148-153. 
Collins, J. \& White, G. (1993), Selection of Auckland medical students over 25 years: a time for change?, Medical Education, 27, 4, pp. 321327.

Dogra, N., Edwards, R., Karim, K. \& Cavendish, S.(2008) Current issues in undergraduate psychiatry education: the findings of a qualitative study, Advances in Health Sciences Education, 13, 3, pp.309-323.

Dolmans, D., Wolfhagen, I., Heineman, E. \& Scherpbier, A. (2008) Factors adversely affecting student learning in the clinical learning environment: A student perspective, Educ Health, 21, 3, pp. 32-41.

Driessen, E., Tartwijk, J. \& Dornan, T. (2008) The self critical doctor: helping students become more reflective, $B M J, 336,7648$, pp. 827-830.

Field, A.P (2005) Discovering statistics using SPSS : And sex, drugs and rock'n'roll, 2nd edn, SAGE, London.

Henning, M., Hazell, W. \& Shulruf, B. (2011) January 29, Teach the teacher series, Poster presented at the 8th Asia Pacific Medical Education Conference (APMEC), NUS Yong Loo Lin School of Medicine, Singapore.

Johansson, J., Skeff, K. \& Stratos, G. (2009) Clinical teaching improvement: The transportability of the Stanford Faculty Development Program, Medical Teacher, 31, 8, pp. 377-382.

Lake, F.R (2004) Teaching on the run tips: doctors as teachers, Medical Journal of Australia, 180, 8, pp.415-418.

Masunaga, H. \& Hitchcock, M.A (2010) Residents' and faculty's beliefs about the ideal clinical teacher, Fam Med, 42, 2, pp. 116-120.

McCann, L., Naden, G. \& Child, S. (2009) Doctors as teachers: what do they think? New Zealand Medical Journal, 122, 1292.

Mckimm, J, Wilkinson, T, Poole, P \& Bagg, W 2010 ,'The current state of undergraduate medical education in New Zealand', Medical Teacher, vol. 32, no. 6, pp. 456-460.

Molenaar, W., Zanting, A., Van Beukelen, P., de Grave, W., Baane, J., Bustraan, J., Engbers, R., Fick, T.E., Jacobs, J. \& Vervoorn, J. (2009) A framework of teaching competencies across the medical education continuum, Medical Teacher, 31, 5, pp.390-396.

Nair, B., Coughlan, J. \& Hensley, M. (1998) Impediments to bed-side teaching, Medical Education, 32, pp. 159-162.

Neher, J., Gordon, K., Meyer, B. \& Stevens, N. (19920 A five-step" microskills" model of clinical teaching, The Journal of the American Board of Family Practice, 5, 4, pp. 419-24. New Zealand Medical Students' Association, October 1, Increase in medical school places welcomed, but retention still an issue, says
Students' Association, New Zealand. Availableat: <http://www.medicalnewstoday. com/articles/123794.php>. [February 7].

Pinnock, R., Shulruf, B., Hawken, S.J, Henning, M.A. \& Jones, R. (2011), Students' and clinical teachers' the clinical learning environment, New Zealand Medical Journal, 124, 1334, pp.63-70.

Poole, P., Moriarty, H., Wearn, A., Wilkinson, T. \& Weller, J. (2009) Medical student selection in New Zealand: Looking to the future, The New Zealand Medical Journal, 122, 1306, pp. 88100.

Prideaux, D., Roberts, C., Eva, K., Centeno, A., Mccrorie, P., Mcmanus, C., Patterson, F., Powis, D., Tekian, A. \& Wilkinson, D. (2011) Assessment for selection for the health care professions and specialty training: Consensus statement and recommendations from the Ottawa 2010 Conference, Medical Teacher, 33, 3, pp. 215-223.

Reed, D., Levine, R., Miller, R., Ashar, B., Bass, E., Rice, T. \& Cofrancesco Jr, J. (2007) Effect of residency duty-hour limits: views of key clinical faculty, Archives of Internal Medicine, 167, 14, pp.1487-1492.

Roberts, C., Lawson, M., Newble, D. \& Self, A. (2003) Managing the learning environment in undergraduate medical education: the Sheffield approach, Medical Teacher, 25, 3, pp. 282-286.

Sanders, C. (2003) Application of Colaizzi's method: Interpretation of an auditable decision trail by a novice researcher, Contemporary Nurse, 14, 3, pp. 292-302.

Schwartz, A. (2010)Resident/Fellow Evaluation of Clinical Teaching: An Essential Ingredient of Effective Teacher Development and Educational Planning, Anesthesiology, 113, 3, p. 516.

Shulruf, B., Hattie, J. \& Tumen, S. (2008) The predictability of enrolment and first year university results from secondary school performance, Studies in Higher Education, 33, 6, 685-698.

Steinert, Y. (2008) Teaching Rounds: The "problem" junior: whose problem is it?, BMJ: British Medical Journal, 336, 7636, pp. 150-153. Availablefrom: <http://www.fmhs.auckland.ac. nz/faculty/undergrad /mbchb/mbchb.aspx>. [February 6].

Wright, S.M. \& Beasley, B.W. (2004) Motivating factorsfor academic physicians within departments of medicine, Mayo Clinic Proceedings, 79, 9, pp. $1145-1150$.

Zibrowski, E.M, Weston, W.W \& Goldszmidt, M.A (2008) 'I don't have time': issues offragmentation, prioritisation and motivation for education scholarship among medical faculty, Medical Education,42, 9 pp. 872-878. 